\title{
Nasal proportional assist ventilation unloads the inspiratory muscles of stable patients with hypercapnia due to COPD
}

\author{
G. Polese*, M. Vitacca\#, L. Bianchi ${ }^{\#}$, A. Rossi**, N. Ambrosino ${ }^{\#}$
}

\begin{abstract}
Nasal proportional assist ventilation unloads the inspiratory muscles of stable patients with hypercapnia due to COPD. G. Polese, M. Vitacca, L. Bianchi, A. Rossi, N. Ambrosino. (C) ERS Journals Ltd 2000 .

ABSTRACT: This study was undertaken to assess the physiological effects of proportional assist ventilation (PAV), administered noninvasively through a nose mask, on ventilatory pattern, arterial blood gases, lung mechanics, and inspiratory muscle effort in stable, hypercapnic patients with chronic obstructive pulmonary disease.

In 15 patients, PAV was set by adjusting volume assist (VA) and flow assist (FA) according to the "run-away" technique and the patient's comfort respectively. The level of support was fixed at $80 \%$ of the total possible assistance and averaged $13.9 \pm 4.1 \mathrm{cmH}_{2} \mathrm{O} \cdot \mathrm{L}^{-1}$ and $4.1 \pm 1.3 \mathrm{cmH}_{2} \mathrm{O} \cdot \mathrm{L}^{-1} \cdot \mathrm{s}$ for VA and $\mathrm{FA}$, respectively. Continuous positive airway pressure (CPAP) was established at $2 \mathrm{cmH}_{2} \mathrm{O}$ and then increased to $5 \mathrm{cmH}_{2} \mathrm{O}$. Physiological measurements were made during spontaneous breathing (SB), after more than $40 \mathrm{~min}$ of PAV, and $20 \mathrm{~min}$ after the rise in CPAP.

On average, PAV improved ventilation $\left(10.3 \pm 2.1\right.$ to $\left.12.5 \pm 2.0 \mathrm{~L} \cdot \mathrm{m}^{-1}\right)$, tidal volume $(0.60 \pm 0.11$ to $0.76 \pm 0.24 \mathrm{~L})$, arterial oxygen tension and arterial carbon dioxide pressure (from 6.7 \pm 0.7 to $7.1 \pm 0.9$ and from $7.6 \pm 1.0$ to $7.2 \pm 1.2 \mathrm{kPa}$, respectively). During SB, pulmonary resistance and dynamic lung elastance averaged 15.0 \pm 7.6 $\mathrm{cmH}_{2} \mathrm{O} \cdot \mathrm{L}^{-1} \cdot \mathrm{s}$ and $15.8 \pm 8.0 \mathrm{cmH}_{2} \mathrm{O} \cdot \mathrm{L}^{-1}$, respectively. Assuming a normal chest wall elastance $\left(5 \mathrm{cmH}_{2} \mathrm{O} \cdot \mathrm{L}^{-1}\right), \mathrm{VA}$ and $\mathrm{FA}$ relieved respectively $\sim 70 \%$ of the elastic and $30 \%$ of the resistive burden, with PAV set with the procedure of this study. The overall magnitude of the patients' inspiratory effort, measured by means of the oesophageal and diaphragmatic pressure time product in 10 patients was significantly reduced by PAV, on average, $328 \pm 122$ to $226 \pm 118(-31 \%)$ and $361 \pm 119$ to $254 \pm 126(-30 \%)$ $\mathbf{c m H}_{2} \mathrm{O} \cdot \mathrm{min}^{-1}$, respectively. In 10 patients the electrical activity of the diaphragm (Edi) was also reduced by PAV to $\sim 70 \%$, on average, of the SB activity. The rise of CPAP 2 $5 \mathrm{cmH}_{2} \mathrm{O}$ did not cause any further significant change in the physiological variables. In all instances there was a good patient-ventilator interaction, the ventilatory breath never entering into the patient's neural expiratory time.

These data show that nasal proportional assist ventilation can provide physiological benefits to the stable hypercapnic chronic obstructive pulmonary disease patients. In fact, proportional assist ventilation, which was well tolerated by all patients, unloaded the inspiratory muscles and improved arterial blood gases. Further studies can clarify whether these beneficial physiological effects of nasal proportional assist ventilation can bear profitable consequences in the overall clinical management of chronic obstructive pulmonary disease patients with chronic carbon dioxide retention.

Eur Respir J 2000; 16: 491-498.
\end{abstract}

\begin{abstract}
*Centro Regionale Fibrosi Cistica, Azienda Ospedaliera di Verona, Verona, Italy. \#Divisione di Pneumologia, Fondazione "S. Maugeri", Gussago, Italy. **Unità Operativa Pneumologia, Ospedali Riuniti di Bergamo, Bergamo, Italy.
\end{abstract}

Correspondence: A. Rossi

Unità Operativa Pneumologia

Ospedali Riuniti di Bergamo

Largo Barozzi 1

I-24100 Bergamo

Italy

Fax: 39035266674

Keywords: Chronic obstructive pulmonary disease

chronic respiratory failure

mechanical ventilation

proportional assist ventilation

respiratory muscles

Received: June 131999

Accepted after revision March 82000

This work has been supported by Telethon, Grant no. 407, Rome, Italy, and by Respironics Inc, Murrysville PA, USA.
In recent studies $[1,2]$, it has been shown that proportional assist ventilation (PAV) [3] can improve the breathing pattern and arterial blood gases during tidal breathing and decrease breathlessness during exercise in stable patients with chronic respiratory failure $(\mathrm{CRF})$ and carbon dioxide $\left(\mathrm{CO}_{2}\right)$ retention. However, to understand whether PAV may play a role in the management of those patients, its effect on the patient's lung and respiratory muscle mechanics should also be investigated. Indeed, an important goal of mechanical ventilation is to unload the patient's inspiratory muscles. To the authors knowledge, this issue has been addressed using PAV in patients with acute respiratory failure [4-8], but not in patients with CRF. There can be a substantial difference between acute and chronic patients. The former are in respiratory distress and need of ventilatory assistance whereas the latter are in a steady state condition without respiratory distress at rest. Hence the impact of mechanical ventilation in patients with CRF cannot be predicted from studies on patients with acute respiratory failure, because a different reaction may be observed when ventilatory assistance is offered, in particular with PAV, which is a patient-guided ventilatory mode. Furthermore, under conditions of full alertness, and without a major chemical stimulus, as it is the case for the stable awake patients of this study, it is possible that most of the respiratory drive originates from nonchemical sources, the so-called consciousness factor. Under these circumstances, an improvement in the 
neuroventilatory coupling due to PAV might not result in reduction of respiratory motor output but in substantial hyperventilation.

Therefore, this study was undertaken to assess the effects of noninvasive PAV on lung mechanics and inspiratory muscle effort in stable patients with chronic hypercapnia due to chronic obstructive pulmonary disease (COPD).

\section{Materials and methods}

The investigative protocol was approved by the Institutional Ethics Committees (S. Maugeri Foundation, Gussago, and Azienda Ospedaliera di Verona, Italy) and was conducted according to the declaration of Helsinki. Informed consent was obtained from the patients before enrolment into the study.

\section{Patients}

Fifteen patients with chronic respiratory insufficiency due to COPD were recruited for this study. Diagnosis of COPD was made according to the indications of the European Respiratory Society [9]. Arterial oxygen tension $\left(\mathrm{Pa}, \mathrm{O}_{2}\right)$ and carbon dioxide tension $\left(\mathrm{Pa}, \mathrm{CO}_{2}\right)$ had to be $<7.9$ and $>5.9 \mathrm{kPa}$ respectively, during spontaneous breathing of room air, at the time of the study. The diagnosis of chronic $\mathrm{CO}_{2}$ retention was based on the clinical record showing values of $P \mathrm{a}, \mathrm{CO}_{2}>5.9 \mathrm{kPa}$, in the months if not years preceding the study, associated with functional evidence of COPD. At the time when they were recruited for this study, the patients were all in stable condition, as assessed by stability in blood gas values and $\mathrm{pH}(>7.35)$, and were free from exacerbations in the preceding four weeks. In addition to a recent exacerbation, exclusion criteria were the following. Firstly, in order to recruit patients in whom CRF due to COPD was the major diagnosis and clinical problem, patients with other chronic organ failure (e.g. renal, hepatic, cardiac failure documented by certified clinical history), and patients with cancer were excluded from the study. Secondly, patients with inability to cooperate were also excluded. All patients were on long-term oxygen therapy. Four patients were on long-term home noninvasive positive pressure ventilation (NPPV) for a few months, in the Pressure Support (PSV) mode with a bi-level ventilator (BIPAP $\mathrm{R}$, Respironics Inc, Murrysville, PA, USA) using the ventilator, by choice, for four periods of 45-60 min during the day and not during the night. Three other patients experienced NPPV, for acute exacerbation, in the months before the study. All the patients received regular treatment with inhaled bronchodilators and neither systemic nor inhaled steroids, apart from exacerbations. Patients were examined $\sim 2 \mathrm{~h}$ after inhalation of their bronchodilating medications. Patients' characteristics are illustrated in table 1.

\section{Measurements}

Routine static and dynamic lung volumes were measured by means of a Collins type 13 I spirometer (Biomedin,
Table 1. - Demographic, anthropometric and functional characteristics of patients in the study

\begin{tabular}{lc}
\hline Patients n & \\
Sex M/F & 15 \\
Age yrs & $12 / 3$ \\
Height cm & $65 \pm 6$ \\
Weight kg & $167 \pm 8$ \\
FEV1 \% pred & $68 \pm 13$ \\
VC \% pred & $23 \pm 6$ \\
FEV1/VC & $46 \pm 19$ \\
TLC \% pred & $0.42 \pm 0.13$ \\
\hline
\end{tabular}

Data are presented as mean $\pm \mathrm{SD}$. M: male; F: female; FEV1: forced expiratory volume in one second; VC: vital capacity; TLC: total lung capacity.

Padova, Italy) or a volume constant body plethysmograph (CAD-NET system 1085; Medical Graphic Corp, St. Paul, MN, USA) with the patient in the seated position according to standard procedure [10] from days to weeks before the study (table 1).

For the experimental procedure of this study, flow $\left(V^{\prime}\right)$ was measured by means of a heated pneumotachograph (Fleisch no.1; Fleisch, Lausanne, Switzerland) connected to a Hewlett-Packard 47304A flow transducer (HewlettPackard, Cuppertino, CA, USA). The pneumotachograph was inserted between the nasal mask and the "plateau valve" of the PAV circuit [11]. Volume $(V)$ was obtained by numerical integration of the flow signal. Pressure at the airway-opening $(P$ ao $)$ was measured with a differential pressure transducer (Honeywell 143PC03D; Honeywell, Freeport, IL, USA) connected to one port of the nasal mask. Changes in pleural $(P \mathrm{pl})$ and abdominal $(P \mathrm{ab})$ pressures were estimated from changes in oesophageal $\left(P_{\text {oes}}\right)$ and gastric $(P$ ga $)$ pressures, respectively (Transducer Motorola X2010 $\pm 100 \mathrm{cmH}_{2} \mathrm{O}$; Colligo, Elekton, Agliano Terme, Italy), by means of the balloon-catheter technique, as described in detail elsewhere [12]. Transpulmonary $(P \mathrm{~L})$ and transdiaphragmatic $(P \mathrm{di})$ pressures were obtained by subtraction of $P$ oes from $P$ ao and $P$ ga, respectively.

\section{Diaphragmatic electromiography}

The diaphragmatic electromyogram (Edi) was recorded with bipolar surface electrodes placed on the right sixthseventh intercostal spaces, close to the anterior costal border [13]. Muscle action potentials ("raw") were electrically filtered $(10-1,000 \mathrm{~Hz})$ and amplified in order to obtain a signal in the range of $-10-10$ volts (Tektronix TM502A; Tektronix UK Ltd, Bracknell, Berkshire, UK). The raw Edi signal was digitally filtered with a high pass filter with a cut-off frequency of $40 \mathrm{~Hz}$, to remove movement artefact and the electrocardiogram (ECG) signal as much as possible (without significantly filtering Edi). From the filtered Edi signal the total time duration of the Edi activity ( $t$,Edi) was computed as well as the time between the onset of one burst of activity and the onset of the next Edi burst (ttot,Edi) [14]. This approach makes it possible to define more precisely the phase relationship of the on-switch and off-switch of the diaphragm with cycling of the ventilator. The Edi was digitally rectified and the integral of the rectified Edi signal over $t$,Edi was computed. This value was then multiplied by respiratory 
frequency to obtain the electric power spent by the diaphragm over one minute (Edi,int).

\section{Breathing pattern}

Tidal volume $(V \mathrm{~T})$, respiratory frequency $(f \mathrm{R})$, minute ventilation $\left(V^{\prime} \mathrm{E}\right)$, and inspiratory capacity (IC) were computed from the volume signal. Total cycle duration ( $t$ tot), inspiratory time $(t \mathrm{I})$, expiratory time $(t \mathrm{E})$ and $t \mathrm{I} / t \mathrm{tot}$, were calculated from the flow signal.

\section{Pulmonary mechanics}

Dynamic intrinsic positive end-expiratory pressure (PEEPi,dyn) was measured as the negative deflection in $P$ oes from the onset of the inspiratory effort to the start of the inspiratory flow. In the presence of expiratory muscle activity, the decrease in $P$ ga was subtracted from the fall in $P_{\text {oes }}$ in the same interval as suggested by APPENDINI et al. [12]. PL was used to calculate pulmonary resistance at mid inspiration $(R \mathrm{~L})$ and dynamic lung elastance $($ Edyn, $\mathrm{L})$ according to the Mead and Whittemberger [15] technique.

\section{Inspiratory muscle pressures}

Changes in the magnitude of the inspiratory muscle effort were estimated from changes in $P_{\mathrm{oes}}$ and $P \mathrm{di}$, as previously described [12]. $P$ oes and $P$ di tidal swings were measured as well as the pressure-time product for the inspiratory muscles (PTPoes) and the diaphragm (PTPdi) also corrected per L of ventilation (PTPoes $/ V^{\prime} \mathrm{E}$ and PTPdi/ $\left.V^{\prime} \mathrm{E}\right)$.

\section{Setting of proportional assist ventilation}

PAV was delivered through a commercial nasal mask (Respironics) by means of a prototype portable ventilator able to compensate for leaks (Respironics), as in the previous studies $[1,2]$. The ventilator delivers PAV according to the equation of motion generating a pressure in proportion to a patient's spontaneous effort. A portion of the total mechanical workload, i.e. elastance and resistance, is taken over according to a level of assistance, which has been decided by the caregiver and can specifically unload the resistive burden (flow assist: FA) and the elastic burden (volume assist: VA). As in previous studies [1, 2], $\mathrm{VA}$ and FA were set initially at the minimum value of 2 $\mathrm{cmH}_{2} \mathrm{O} \cdot \mathrm{L}^{-1}$ and $1 \mathrm{cmH} \mathrm{H}_{2} \mathrm{O} \cdot \mathrm{L}^{-1} \cdot \mathrm{s}^{-1}$, respectively, in all patients. Then, leaving FA unchanged, VA was increased slowly by steps of $2 \mathrm{cmH}_{2} \mathrm{O} \cdot \mathrm{L}^{-1}$ until the pattern of the "run-away" was observed. To set FA, a similar stepwise approach to the one described above was used, by keeping VA at $2 \mathrm{cmH}_{2} \mathrm{O} \cdot \mathrm{L}^{-1}$ and slowly increasing FA from 1 $\mathrm{cmH}_{2} \mathrm{O} \cdot \mathrm{L}^{-1} \cdot \mathrm{s}^{-1}$ by small steps of $1 \mathrm{cmH}_{2} \mathrm{O} \cdot \mathrm{L}^{-1} \cdot \mathrm{s}^{-1}$ until either the unstable flow and pressure tracings appeared, or the patient notified that they felt uncomfortable with that level of assistance. Then, FA and VA were set at $80 \%$ of the last level at which the patient felt comfortable (table 2). A value of continuous positive airway pressure
Table 2. - Proportional assist ventilation settings

\begin{tabular}{lcc}
\hline Patient & $\begin{array}{c}\text { Flow assist } \\
\mathrm{cmH}_{2} \mathrm{O} \cdot \mathrm{L}^{-1} \cdot \mathrm{s}\end{array}$ & $\begin{array}{c}\text { Volume assist } \\
\mathrm{cmH}_{2} \mathrm{O} \cdot \mathrm{L}^{-1}\end{array}$ \\
\hline 1 & 1.6 & 14.4 \\
2 & 3.2 & 14.4 \\
3 & 4.0 & 12.0 \\
4 & 4.0 & 10.4 \\
5 & 4.8 & 19.2 \\
6 & 4.0 & 9.6 \\
7 & 2.4 & 12.0 \\
8 & 5.6 & 12.0 \\
9 & 3.2 & 19.2 \\
10 & 4.0 & 7.2 \\
11 & 4.0 & 12.8 \\
12 & 6.4 & 12.8 \\
13 & 6.4 & 12.8 \\
14 & 3.2 & 22.4 \\
15 & 4.0 & 17.6 \\
\hline
\end{tabular}

(CPAP) of $2 \mathrm{cmH}_{2} \mathrm{O}$ was mandatorily set by the ventilator. After the setting procedure and before the beginning of our experimental protocol, the leak compensation capability of the ventilator was checked by generating an intentional leak in the mask and observing that the leak estimation algorithm gradually adjusted the unknown leak estimate, so that the total leak estimate equalled the total flow due to the exhalation valve and the unknown leaks. The compensation for unknown leaks occurred in 2-3 consecutive breaths.

\section{Experimental procedure}

The patients were studied in the morning and were free to choose the most comfortable position. All patients adopted a semirecumbent position. In all patients, the skin in the anterior 6-7th intercostal spaces was cleaned to place the surface Edi electrodes. Then, after the application of topical anaesthesia (xylocaine spray 10\%), the patients were asked to swallow two balloon-tipped catheters through the nose into the stomach. Three patients could not swallow the balloons because of excessive discomfort. Hence 12 patients swallowed the oesophageal and gastric balloons. The occlusion test [16] was performed while the patients were breathing through a mouthpiece to verify the correct positioning of the oesophageal balloon, and it was satisfactory in every instance. After the instrumentation of the patients, a commercial nose mask was applied and connected to the pneumotachograph. Special care was taken to ensure mouth closure throughout the procedure. The ventilator circuit was equipped with the Sanders NRV-2 valve (Respironics) to prevent $\mathrm{CO}_{2}$ rebreathing [11]. All measurements were taken at inspiratory oxygen fraction $\left(F \mathrm{I}, \mathrm{O}_{2}\right)$ of 0.21 .

Once the patient was accustomed to the experimental setting and appeared to be relaxed, the steps to set individual VA and FA levels were performed. Then, the patient breathed through the nose mask and the pneumotachograph, having removed the ventilator tubing, for about 20 min. Subsequently, FA and VA were applied separately in random order, each mode of support lasting for about $20 \mathrm{~min}$, for a total of $\sim 40 \mathrm{~min}$, to assess whether the patient's discomfort could occur over a longer period of 
observation than the few minutes initially engaged to establish the level of assistance. After those $40 \mathrm{~min}$, FA and VA were combined to deliver PAV for an additional 40 min. Then, CPAP was increased 2-5 $\mathrm{cmH}_{2} \mathrm{O}$ for an additional $20 \mathrm{~min}$. In two patients the signal from the gastric balloon became unsatisfactory during the course of the experimental procedure. Hence the complete data of lung and respiratory muscle mechanics was available for 10 of the 15 patients. In five patients the Edi signal was lost due to adjustments in the patients' position later in the procedure. The Edi signal was reliable for the complete analysis in 10 of the 15 patients. The $10 / 15$ subjects in whom mechanics was measured were different from the 10/15 subjects who had Edi signal recorded.

Arterial blood was sampled from the radial artery at the end of the spontaneous breathing period and at the end of $\mathrm{PAV}$ with $2 \mathrm{cmH}_{2} \mathrm{O} \mathrm{CPAP}$. Arterial blood gases were measured by means of an ABL 330 (Radiometer, Copenhagen, Denmark) blood gas analyser. To assess possible changes in the end-expiratory lung volume, the inspiratory capacity (IC) at the end of each step, just after collecting the signals. The IC was measured while the patient was on PAV. The patient was asked to perform an IC manoeuvre. As soon as the inspiration started, the ventilator tubing was disconnected from the ventilator, such that the inspiratory act to total lung capacity (TLC) was not supported by PAV.

\section{Data analysis}

All signals were digitized by an analogue-to-digital converter with 12-bit resolution (DT2801/A; Data Translation, Marlboro, MA, USA), connected to a personal computer. The collection and subsequent analysis was performed using the software package LABDAT-ANADAT 5.1 (RHTInfodat, Montreal, Quebec, Canada). All the physiological signals were collected in the last $3 \mathrm{~min}$ of both spontaneous breathing and PAV (with 2 and $5 \mathrm{cmH}_{2} \mathrm{O}$ of CPAP). The analysis of breathing pattern and respiratory mechanics, for the penultimate $2 \mathrm{~min}$ were collected at a sampling frequency of $100 \mathrm{~Hz}$. For the collection of physiological signals during the third minute the sampling frequency was increased to $500 \mathrm{~Hz}$ for Edi analysis. The Data Translation 2801/A AD board with the ANADAT-LABDAT acquisition system had some limitations, which did not allow simultaneous acquisition of signals with different frequencies. Due to the consideration that our previous acquisition did not show in the surface Edi any relevant component in the power spectrum above $200-250 \mathrm{~Hz}$, the acquisition frequency of $500 \mathrm{~Hz}$ according to the Nyquist frequency, was chosen for the Edi.

Using the Abreath facility of ANADAT, the breathing pattern was analysed for two consecutive minutes; the mean values of the variables were used for the subsequent statistical analysis. The values of $P$ oes and $P$ di, both tidal and PTP, were analysed in the same interval, without automatic software facilities, selecting $1 \mathrm{~min}$ of breathing without artefacts (e.g. oesophageal contractions, swallowing, etc.) in the pressure signals. The artefacts are easily recognized by observation of the signals. The analysis of the Edi was performed on 10-12 breaths.

\section{Statistical analysis}

Results are expressed as mean $\pm \mathrm{SD}$. Differences between treatments and within treatment were evaluated by analysis of variance (ANOVA) for repeated measures. Differences between paired groups of data were evaluated with posthoc paired t-test with Bonferroni adjustment and were applied as requested by ANOVA interaction. A p-value $<0.05$ was considered significant.

\section{Results}

All patients tolerated PAV well throughout the procedure. In one patient, sporadic brief periods of spontaneous apnoea $(\sim 20 \mathrm{~s})$ were observed. As shown in table 3, PAV determined a significant increase in $V^{\prime} \mathrm{E}(+21 \%$ on average) mainly due to the greater $V \mathrm{~T}(+27 \%$ on average). Breathing frequency, duty-cycle, and IC essentially did not change. On average, $P_{\mathrm{a}}, \mathrm{CO}_{2}$ and $\mathrm{Pa}_{\mathrm{a}} \mathrm{O}_{2}$ improved by $\sim 0.4 \mathrm{kPa}$ with PAV.

Mean values of the 10 patients' lung mechanics, namely PEEPi,dyn, Edyn,L, and $R \mathrm{~L}$ are shown in table 4 . On average, there was no significant change in lung mechanics throughout the procedure. By contrast, as shown in table 5 , all the indexes of inspiratory muscle effort were significantly reduced by PAV: PTPoes and PTPdi decreasing by $31 \%$ and $30 \%$ respectively, on average. The reduction was slightly greater when the inspiratory muscle effort was corrected for the increase in $V^{\prime} \mathrm{E}$, amounting to $-43 \%$ and $-44 \%$ for PTPoes $/ V^{\prime} \mathrm{E}$ and $\mathrm{PTPdi} / V^{\prime} \mathrm{E}$, respectively on average. As shown in figure 1 , there was a rather consistent behaviour in all the 10 patients in whom those measurements were completed with only one exception. In that patient, application of PAV resulted in a substantial increase in both PTPoes $(+46 \%)$ and PTPdi $(+68 \%)$, associated with a rise in $V^{\prime} \mathrm{E}(+33 \%)$. The corresponding change in PTPoes $/ V^{\prime} \mathrm{E}$ and PTPdi/ $/ V^{\prime} \mathrm{E}$ amounted to $+9 \%$ and $+20 \%$, respectively.

Figure 2 also shows that the electrical activity of the diaphragm was significantly reduced by PAV in the 10 patients in whom Edi was measured. Edi decreased, on average, by $\sim 28 \%$. When corrected for the increase in $V^{\prime} \mathrm{E}$ the reduction averaged $38 \%$.

Table 3. - Ventilatory pattern and arterial blood gases at different settings of proportional assist ventilation (PAV)

\begin{tabular}{lccc}
\hline & $\mathrm{SB}$ & PAV+CPAP 2 & PAV+CPAP 5 \\
\hline$V^{\prime} \mathrm{E} \mathrm{L} \cdot \mathrm{m}^{-1}$ & $10.3 \pm 2.1$ & $12.5 \pm 2.0^{*}$ & $12.0 \pm 2.0$ \\
$V \mathrm{~T} \mathrm{~L}$ & $0.60 \pm 0.11$ & $0.76 \pm 0.24^{*}$ & $0.71 \pm 0.22$ \\
$f \mathrm{R} \mathrm{bpm}$ & $18 \pm 5$ & $18 \pm 6$ & $18 \pm 5$ \\
$t \mathrm{t} / \mathrm{tot}$ & $0.31 \pm 0.05$ & $0.30 \pm 0.06$ & $0.31 \pm 0.06$ \\
$\mathrm{IC} \mathrm{L}$ & $1.27 \pm 0.56$ & $1.35 \pm 0.54$ & $1.38 \pm 0.56$ \\
$P \mathrm{a}, \mathrm{CO}_{2} \mathrm{kPa}$ & $7.6 \pm 1.0$ & $7.2 \pm 1.2^{*}$ & - \\
$P \mathrm{a}, \mathrm{O}_{2} \mathrm{kPa}$ & $6.7 \pm 0.7$ & $7.1 \pm 0.9^{*}$ & - \\
$\mathrm{pH}$ & $7.38 \pm 0.02$ & $7.40 \pm 0.04^{*}$ & - \\
\hline
\end{tabular}

Data are presented as mean \pm SD. SB: spontaneous breathing; CPAP 2: $2 \mathrm{cmH}_{2} \mathrm{O}$ of continuous positive airway pressure; CPAP 5: $5 \mathrm{cmH}_{2} \mathrm{O}$ of CPAP; $V^{\prime} \mathrm{E}$ : minute ventilation; $V \mathrm{~T}$ : tidal volume; $f \mathrm{R}$ : respiratory rate; $t \mathrm{t} / \mathrm{t}$ tot: ventilatory duty cycle; IC: inspiratory capacity; $P_{a}, C_{2}$ : arterial $\mathrm{CO}_{2}$ pressure; $P \mathrm{a}, \mathrm{O}_{2}$ : arterial $\mathrm{O}_{2}$ pressure; *: $\mathrm{p}<0.05$ versus $\mathrm{SB}$. 
Table 4. - Lung mechanics at different settings of proportional assist ventilation (PAV)

\begin{tabular}{|c|c|c|c|}
\hline & SB & PAV+CPAP 2 & $\mathrm{PAV}+\mathrm{CPAP} 5$ \\
\hline $\mathrm{PEEPi}$,dyn $\mathrm{cmH}_{2} \mathrm{O}$ & $2.6 \pm 1.5$ & $2.3 \pm 1.5$ & $1.6 \pm 1.0$ \\
\hline$E$ dyn,L cmH $2 \mathrm{O} \cdot \mathrm{L}^{-1}$ & $15.8 \pm 8.0$ & $13.8 \pm 7.4$ & $13.2 \pm 7.6$ \\
\hline$R \mathrm{~L} \mathrm{cmH}{ }_{2} \mathrm{O} \cdot \mathrm{L}^{-1} \cdot \mathrm{s}^{-1}$ & $15.0 \pm 7.6$ & $15.8 \pm 7.9$ & $14.1 \pm 6.3$ \\
\hline
\end{tabular}

Data are presented as mean $\pm \mathrm{SD}$. SB: spontaneous breathing; CPAP 2: $2 \mathrm{cmH}_{2} \mathrm{O}$ of continuous positive airway pressure; CPAP 5: $5 \mathrm{cmH}_{2} \mathrm{O}$ of CPAP; PEEPi,dyn: intrinsic dynamic positive end-expiratory pressure; Edyn,L: dynamic lung elastance; RL: lung resistance.

The rise in CPAP from $2-5 \mathrm{cmH}_{2} \mathrm{O}$ did not cause any significant change in the breathing pattern as well as in the magnitude of the patients' inspiratory effort.

To analyse the patient-ventilator synchrony, the breathing frequency from the Edi signal and from the flow signal was measured. Figure 3 illustrates an example of Edi activity during PAV, showing that the ventilator assistance was always synchronous with the patient's inspiratory effort. Figure $4 \mathrm{a}$ shows that there was a complete correspondence between the patient's neural frequency of breathing and the ventilator frequency. Furthermore, figure $4 \mathrm{~b}$ also shows that the neuromuscular duration of inspiration was never shorter than the inspiration measured on the flow signal, indicating that the ventilator did not compromise the time available for expiratory flow. The end of the ventilator cycle during PAV occurred almost simultaneously with the end of the electrical activity, never extending into the neuromuscular expiratory time. Furthermore, in the 10 patients in whom $P$ di was measured the mechanical inflation never extended beyond the point where $P$ di reached baseline.

\section{Discussion}

The results of this study show that, in stable hypercapnic patients with severe COPD, short term, noninvasive application of PAV: 1) improves ventilation and arterial blood

Table 5. - Inspiratory effort at different settings of proportional assist ventilation (PAV)

\begin{tabular}{lccc}
\hline & SB & PAV+ & PAV+ \\
& & CPAP 2 & CPAP 5 \\
\hline$\Delta P_{\text {oes }} \mathrm{cmH}_{2} \mathrm{O}$ & $16 \pm 3$ & $12 \pm 5^{*}$ & $9 \pm 5^{*}$ \\
PTPoes $\mathrm{cmH}_{2} \mathrm{O} \cdot \mathrm{min}^{-1}$ & $328 \pm 122$ & $226 \pm 118^{*}$ & $195 \pm 78^{*}$ \\
PTPoes $/ V^{\prime} \mathrm{E} \mathrm{cmH}_{2} \mathrm{O} \cdot \mathrm{min}^{2} \cdot \mathrm{L}^{-1}$ & $18 \pm 5$ & $18 \pm 6$ & $18 \pm 5$ \\
$\Delta P$ di $\mathrm{cmH}_{2} \mathrm{O}$ & $19 \pm 6$ & $13 \pm 6^{*}$ & $11 \pm 5^{*}$ \\
$\mathrm{PTPdi} \mathrm{cmH}_{2} \mathrm{O} \cdot \mathrm{min}^{-1}$ & $361 \pm 119$ & $254 \pm 126^{*}$ & $218 \pm 101^{*}$ \\
PTPdi $/ V^{\prime} \mathrm{E} \mathrm{cmH} \mathrm{cm}_{2} \mathrm{O} \cdot \mathrm{min}^{2} \cdot \mathrm{L}^{-1}$ & $34 \pm 11$ & $19 \pm 10^{*}$ & $19 \pm 12^{*}$ \\
\hline
\end{tabular}

Data are presented as mean \pm SD. SB: spontaneous breathing; CPAP 2: $2 \mathrm{cmH}_{2} \mathrm{O}$ of continuous positive airway pressure;

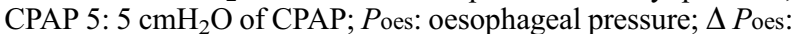
tidal swing of $P$ oes; PTPoes: pressure-time product per minute for the inspiratory muscles; PTPoes $/ V^{\prime} \mathrm{E}$ : pressure-time product per minute for the inspiratory muscles corrected for ventilation; $P$ di: transdiaphragmatic pressure; $\Delta P$ di: tidal swing of $P$ di; PTPdi: pressure-time product per minute for the diaphragm; $\mathrm{PTPdi} / V^{\prime} \mathrm{E}$ : pressure-time product per minute for the diaphragm corrected for ventilation; *: $\mathrm{p}<0.05$ versus $\mathrm{SB}$.
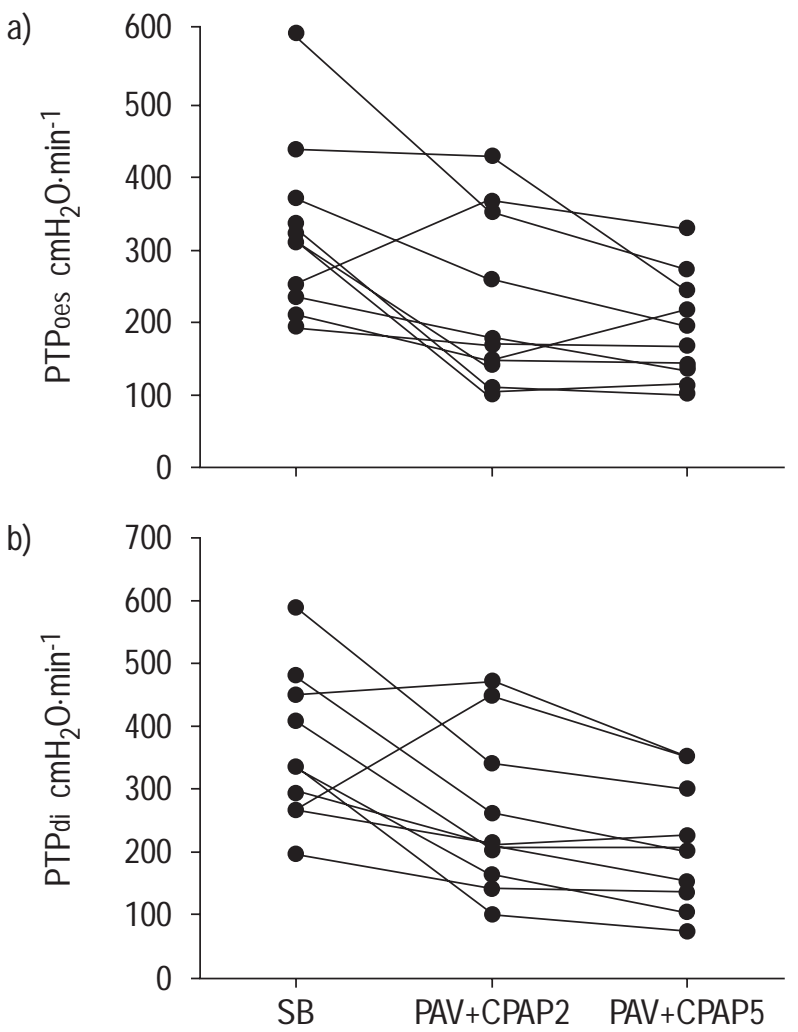

Fig. 1. - Individual values of a) PTPoes and b) PTPdi during spontaneous breathing $(\mathrm{SB})$ and during proportional assist ventilation with $2 \mathrm{cmH}_{2} \mathrm{O}$ continuous positive airway pressure (CPAP 2 ) and with 5 $\mathrm{cmH}_{2} \mathrm{O}$ continuous positive airway pressure (CPAP 5).

gases; 2) unloads the patients' inspiratory muscles; and 3) provides a good patient-ventilator interaction.

Although noninvasive ventilation is mostly applied during night-time in stable hypercapnic patients, it was reasoned that the lack of information on the physiological effect of PAV in those patients would warrant a daytime investigation. In particular when one takes into account the techniques needed to measure patient's respiratory muscle mechanics, for example the oesophageal and gastric balloons. The data of this study confirm and extend previous observations, in patients with chronic respiratory insufficiency from both restrictive and obstructive diseases. It was shown that nasal-mask application of PAV improved the breathing pattern and arterial blood gases [1] and provided ventilatory assistance during exercise in severe nonhypercapnic [17] and hypercapnic [2] stable COPD patients. Other investigators have shown that PAV can unload the inspiratory muscles also in ventilatordependent intubated patients with acute respiratory failure due to exacerbation of COPD $[4,5]$.

In patients similar to those of this study, i.e. stable hypercapnic COPD, and using similar techniques, i.e. surface Edi and oesophageal and gastric balloons, NAVA et al. [13] found that PSV at 10 and $20 \mathrm{cmH}_{2} \mathrm{O}$ also improved arterial blood gases and unloaded the diaphragm. On average, the changes in $\mathrm{Pa}_{\mathrm{a}} \mathrm{CO}_{2}$ and $\mathrm{Pa}, \mathrm{O}_{2}$ were in the same range of the present study, whereas the reduction in PTPdi was slightly greater with levels of assistance $>10 \mathrm{cmH}_{2} \mathrm{O}$ of PSV [13]. However, a comparison between PAV and PSV cannot be carried out between the data of this and 

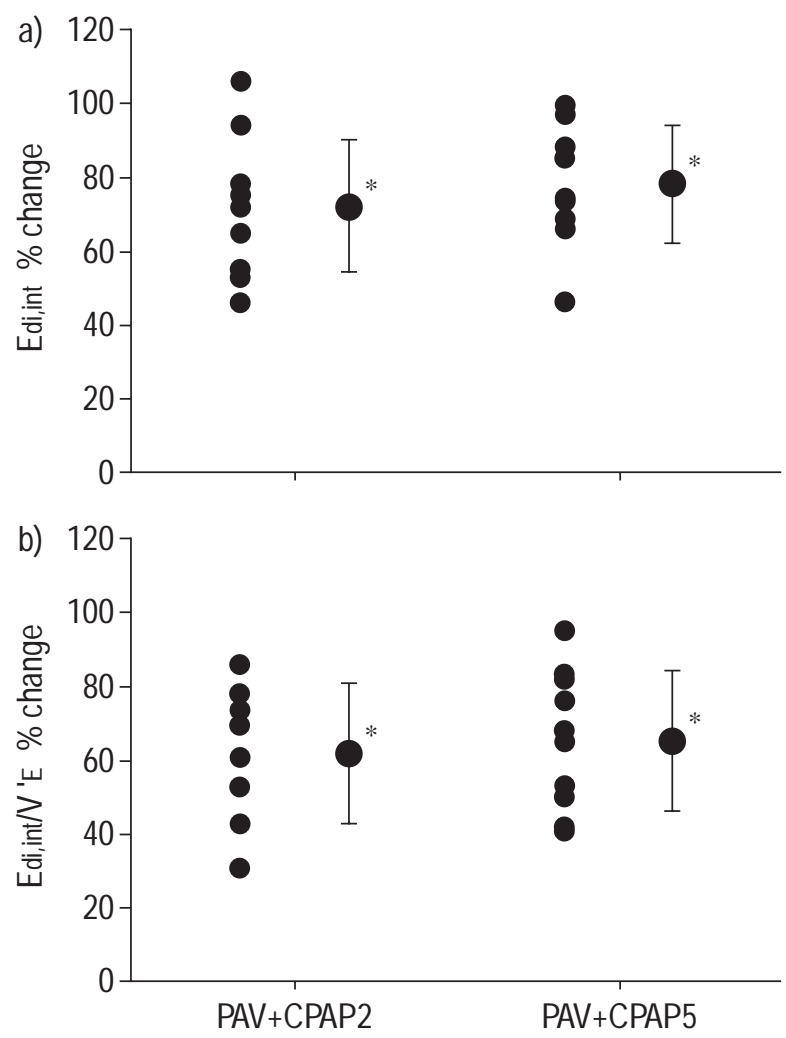

Fig. 2. - Individual and mean \pm SD values of percent changes in a) integrated diaphragmatic electromyographic activity (Edi,int); and b) integrated diaphragmatic electromyographic activity corrected for ventilation $\left(\mathrm{Edi}\right.$, int $\left./ V^{\prime} \mathrm{E}\right)$ from baseline condition, i.e. spontaneous breathing (SB), during proportional assist ventilation with $2 \mathrm{cmH}_{2} \mathrm{O}$ continuous positive airway pressure (CPAP 2) and with $5 \mathrm{cmH}_{2} \mathrm{O}$ continuous positive airway pressure (CPAP 5). *: $\mathrm{p}<0.05$ compared versus SB.

that study because of differences in the setting of the ventilator. Nevertheless, the present study and the study of NAVA et al. [13] show that NPPV either by means of PAV or PSV provides physiological benefits in stable hypercapnic COPD patients. Whether those benefits may support the long-term use of NPPV in those patients for clinical purposes remains to be established in clinical trials [18]. However, it cannot be excluded that the rest provided by NPPV to the inspiratory muscles might be one of the mechanisms underlying the daytime improvement in arterial blood gases following application of nocturnal NPPV [18].

In the present study, any significant additional benefit by increasing CPAP from 2 to $5 \mathrm{cmH}_{2} \mathrm{O}$ was not found. This may not be surprising in view of the small PEEPi,dyn usually found in COPD patients in stable condition. Either physiological or subjective adverse effect increasing CPAP from 2 to $5 \mathrm{cmH}_{2} \mathrm{O}$ was not found. These results suggest that levels of CPAP $>2 \mathrm{cmH}_{2} \mathrm{O}$ are not needed in stable COPD patients.

The comparison between the data of FA and VA (table 2) and the measurements of lung mechanics (table 4)

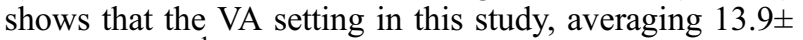
$4.1 \mathrm{cmH}_{2} \mathrm{O} \cdot \mathrm{L}^{-1}$, unloaded a substantial portion of the elastic burden. In fact, baseline dynamic lung elastance averaged $15.8 \pm 8.0 \mathrm{cmH}_{2} \mathrm{O} \cdot \mathrm{L}^{-1}$. Chest wall elastance is generally not altered in stable COPD and can amount to
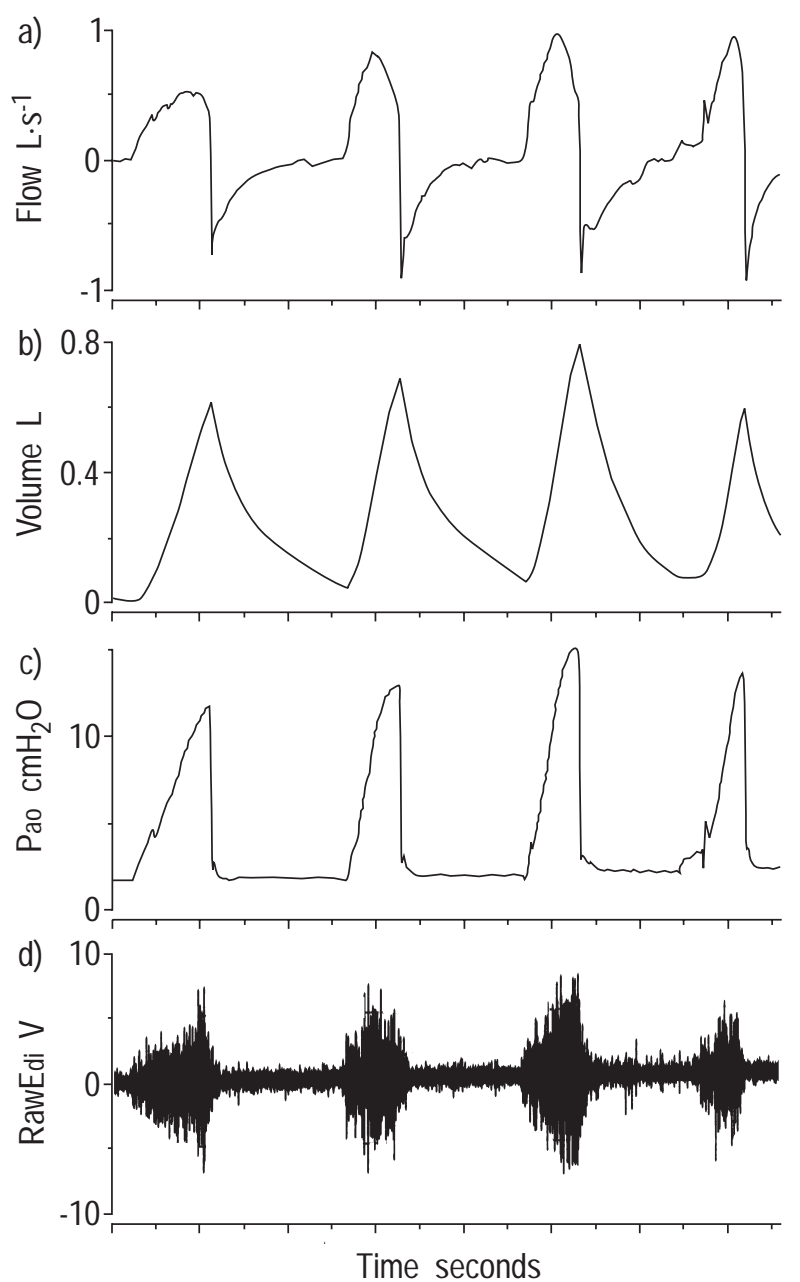

Fig. 3. - Example of breathing pattern during proportional assist ventilation with $2 \mathrm{cmH}_{2} \mathrm{O}$ from one patient. a) flow; b) volume; c) airway opening pressure $(P \mathrm{ao})$; and d) Raw diaphragmatic electromyography (RawEdi).

$\sim 5 \mathrm{cmH}_{2} \mathrm{O} \cdot \mathrm{L}^{-1}$ [19], such that VA unloaded $\sim 70 \%$ of the total elastic load of the respiratory system, which may be estimated to amount to $\sim 20 \mathrm{cmH}_{2} \mathrm{O} \cdot \mathrm{L}^{-1}$ for total elastance, on average, in the COPD patients of our study. By contrast, the level of FA set with our procedure, i.e. $4.1 \pm 1.3$ $\mathrm{cmH}_{2} \mathrm{O} \cdot \mathrm{L}^{-1} \cdot \mathrm{s}$, was substantially lower than inspiratory lung resistance, i.e. $15.0 \pm 7.6 \mathrm{cmH}_{2} \mathrm{O} \cdot \mathrm{L}^{-1} \cdot \mathrm{s}$, chest wall resistance being basically negligible [19], such that only $26 \%$ of the resistive burden was unloaded by the ventilator. The onset of patient's discomfort, which may determine disadaptation to the ventilator, and hence complete failure of any kind of ventilatory assistance precluded higher levels of FA, in this study. As shown by figure 2, one patient increased substantially his motor output with PAV, as shown by the increase in PTP and $V^{\prime} \mathrm{E}$. This was neither due to anxiety or discomfort nor to any characteristic of the patient that could be observed. However, it could have been determined by other consciousness factors in that awake subject.

Though the percent assist was substantially different for VA and FA, this did not alter the fundamental operation of PAV in terms of synchrony between ventilator and patient. In fact, in our patients, the end of the PAV ventilator cycle 

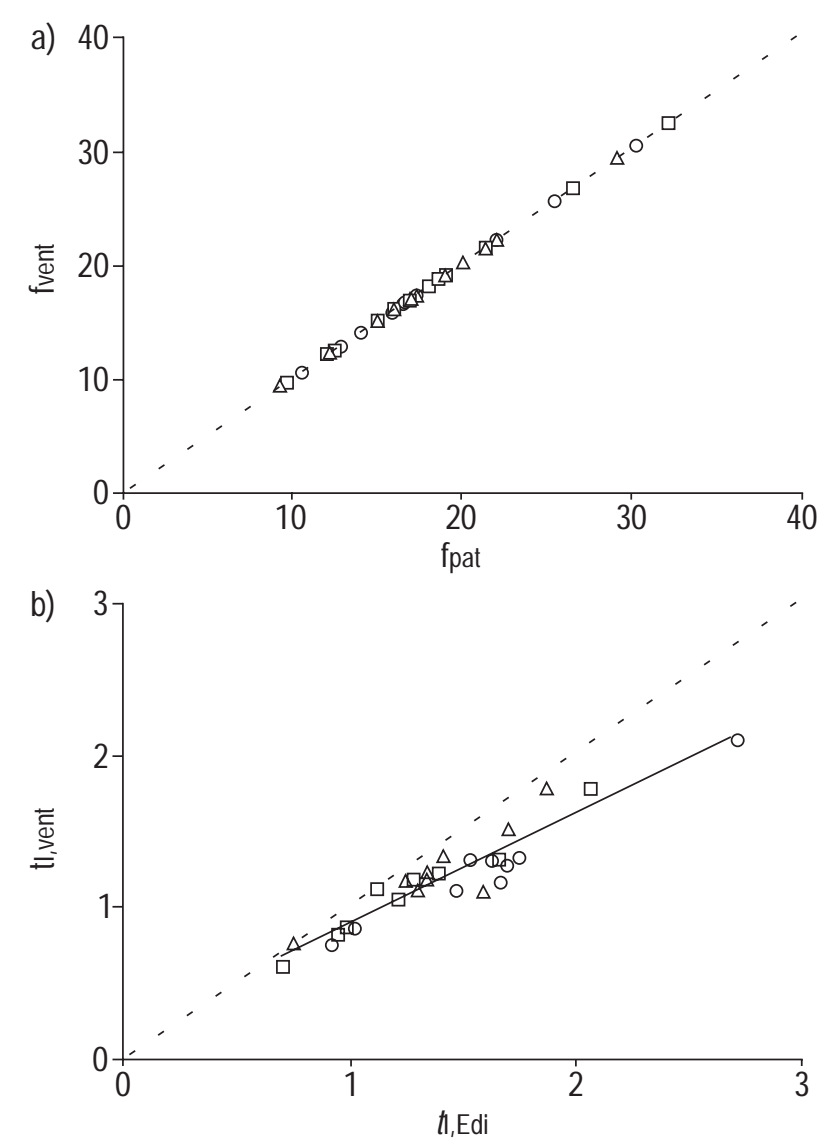

Fig. 4. - a) Relationship between the patients' frequency of breathing, measured on diaphragmatic electromyographic signal (fpat), and the frequency of the ventilator (fvent). b) Relationship between inspiratory time $(t \mathrm{I})$ measured on diaphragmatic electromyographic signal $(t \mathrm{I}, \mathrm{E}, \mathrm{di})$ and the $t \mathrm{I}$ measured on the flow signal ( $t$ I,vent). $\bigcirc$ : spontaneous breathing; $\square$ : proportional assist ventilation (PAV) plus $2 \mathrm{cmH}_{2} \mathrm{O}$ continuous positive airway pressure (CPAP); $\triangle$ : PAV plus $5 \mathrm{cmH}_{2} \mathrm{O}$ CPAP; — : line of identity; - - - - : line of regression.

always occurred during the declining phase of $P$ di, just as in $\mathrm{SB}$, and did not extend beyond the point where $P$ di reached baseline. In these conditions, the PAV ventilatory mode did not compromise the time available for expiratory flow. The patients were getting less assistance than was previously thought, but, since all the patients felt comfortable and no patient-ventilator asynchrony occurred, it is problematical to state that a more precise level of assist was really needed. Partial assistance with patient's comfort may be a reasonable objective for noninvasive ventilation in the chronic setting, in which there is no life-threatening acidosis to be treated or unbearable dyspnoea to be relieved while adaptation of the ventilatory setting to the patient's comfort is essential to make the ventilatory support acceptable, in particular if nocturnal use is planned.

In their noninvasive application of PAV to support exercise in COPD patients, Dolmage and GoldsteIN [17] did not take a numeric approach to adjust VA and FA, but set PAV according to patients' comfort. By contrast, in ventilator-dependent patients $[4,5,8]$, both VA and FA were set upon measurements of respiratory mechanics taken, before the implementation of PAV, by means of the rapid airway occlusion technique. That technique may be simple but requires patient's respiratory muscle relaxa- tion, a condition easy to obtain in ventilator-dependent intubated patients, but not in awake patients, reacting to the airway occlusion. In this study, patients' lung mechanics were measured by means of the oesophageal balloon. However, the approach of setting the PAV was deliberately chosen in a way that can be extended to the clinical application of nasal PAV for chronic patients, without requiring invasive techniques and peculiar patient's condition, such as respiratory muscle relaxation. Future research might help to figure out whether some noninvasive measurements of patient's respiratory mechanics could provide some improvement to tailor individual PAV.

In summary, in the short-run application to awake, chronic, stable, hypercapnic COPD patients without respiratory distress, proportional assist ventilation, a patientguided mode of ventilatory support, produced a significant reduction in the magnitude of the inspiratory effort, also improving arterial blood gases and ventilation. Hence, proportional assist ventilation can be considered a new addition to other conventional modes of mechanical ventilation for the patients with chronic respiratory insufficiency.

\footnotetext{
Acknowledgements. The authors are indebted to $\mathrm{M}$. Younes, Winnipeg, Canada for his helpful comments to the interpretation of our data and for his precious contribution to the discussion of the results. The authors also thank A. Serra, for critical revision of the manuscript, and acknowledge the technical assistance of A. Ciucci in the preparation of the manuscript.
}

\section{References}

1. Ambrosino N, Vitacca M, Polese G, Foglio K, Rossi A. Short-term effects of nasal proportional assist ventilation in patients with chronic hypercapnic respiratory insufficiency. Eur Respir J 1997; 10: 2829-2834.

2. Bianchi L, Foglio K, Pagani M, Vitacca M, Rossi A, Ambrosino N. Effect of nasal proportional assist ventilation (PAV) on exercise performance and breathlessness of COPD patients with chronic hypercapnia. Eur Respir $J$ 1998; 11: 422-427.

3. Younes M. Proportional assist ventilation. In: Tobin MJ, ed. Principles and Practice of Mechanical Ventilation. New York, McGraw-Hill, 1994; pp. 349-370.

4. Ranieri MV, Giuliano R, Mascia L, et al. Patientventilator interaction during acute hypercapnia: pressuresupport vs proportional-assist ventilation. J Appl Physiol 1996; 81: 426-436.

5. Navalesi P, Hernandez P, Wongsa A, Laporta D, Goldberg $\mathrm{P}$, Gottfried SB. Proportional assist ventilation in acute respiratory failure: effects on breathing pattern and inspiratory effort. Am J Respir Crit Care Med 1996; 154 : 1330-1338.

6. Marantz S, Patrick W, Webster K, Roberts D, Oppenheimer L, Younes M. Responses of ventilator dependent patients to different levels of proportional assist. $J$ Appl Physiol 1996; 80: 397-403.

7. Patrick W, Webster K, Ludwig L, Roberts D, Wiebe P, Younes M. Noninvasive positive-pressure ventilation in acute respiratory distress without prior chronic respiratory failure. Am J Respir Crit Care Med 1996; 153: 10051011.

8. Ranieri MV, Grasso S, Mascia L, et al. Effects of 
proportional assist ventilation on inspiratory muscle effort in patients with chronic obstructive pulmonary disease and acute respiratory failure. Anesthesiol 1997; 86: 79-91.

9. Siafakas NM, Vermeire P, Pride NB, et al., on behalf of the Task Force. Optimal assessment and management of chronic obstructive pulmonary disease (COPD). Eur Respir J 1995; 8: 1398-1420.

10. Official Statement of the European Respiratory Society. Standardized lung function testing. Eur Respir J 1993; 6: $1-100$.

11. Ferguson T, Gilmartin G. $\mathrm{CO}_{2}$ rebreathing during BiPAP ventilatory assistance. Am J Respir Crit Care Med 1995; 151: 1126-1135.

12. Appendini L, Patessio A, Zanaboni S, et al. Physiological effects of positive end expiratory pressure and mask pressure support during exacerbations of chronic obstructive pulmonary disease. Am J Respir Crit Care Med 1994; 149: 1069-1076.

13. Nava S, Ambrosino N, Rubini F, et al. Effect of nasal pressure support ventilation and external PEEP on diaphragmatic activity in patients with severe stable COPD. Chest 1993; 103: 143-150.
14. Parthasarathy S, Jubran A, Tobin MJ. Cycling of inspiratory and expiratory muscle groups with the ventilator in airflow limitation. Am J Respir Crit Care Med 1998; 158: 1471-1478.

15. Mead J, Whittenberger JL. Physical properties of human lungs measured during spontaneous respiration. $J \mathrm{Appl}$ Physiol 1953; 5: 770-796.

16. Baydur A, Behrakis K, Zin WA, Jaeger M, Milic-Emili J. A simple method for assessing the validity of the esophageal balloon technique. Am Rev Respir Dis 1982; 126: 788-791.

17. Dolmage TE, Goldstein RS. Proportional assist ventilation and exercise tolerance in subjects with COPD. Chest 1997; 111: 948-954.

18. Meecham Jones DJ, Paul EA, Jones PW, Wedzicha JA. Nasal pressure support ventilation plus oxygen compared with oxygen therapy alone in hypercapnic COPD. Am J Respir Crit Care Med 1995; 152: 538-544.

19. De Troyer A, Pride NB. In: Roussos C, ed. The Chest Wall and Respiratory Muscles in Chronic Obstructive Pulmonary Disease. The Thorax. New York, Marcel Dekker Inc., 1994; pp. 1975-2006. 